\title{
Correction to: Building Compassionate Schools: Pilot Study of a Compassionate Mind Training Intervention to Promote Teachers' Well-being
}

\author{
Marcela Matos $^{1}$ (D) $\cdot$ Lara Palmeira $^{1,2}$ (D) Isabel Albuquerque ${ }^{1}$ (D) Marina Cunha $^{1,3}$ (D) Margarida Pedroso Lima $^{1}$ (D) \\ Ana Galhardo ${ }^{1,3}$. Frances A. Maratos ${ }^{4}$. $\cdot$ Paul Gilbert ${ }^{5}$ (D)
}

Published online: 5 February 2022

(c) Springer Science+Business Media, LLC, part of Springer Nature 2022

\section{Correction to: Mindfulness \\ https://doi.org/10.1007/s12671-021-01778-3 \\ https://doi.org/10.1007/s12671-021-01796-1}

In the original and correction articles of "Building Compassionate Schools: Pilot Study of a Compassionate Mind Training Intervention to Promote Teachers' Well-being" by Marcela Matos, Lara Palmeira, Isabel Albuquerque, Marina Cunha, Margarida Pedroso Lima, Ana Galhardo, Frances A. Maratos and Paul Gilbert (Mindfulness. Advance online publication. 2021. https://doi.org/10.1007/s12671-02101778-3 and https://doi.org/10.1007/s12671-021-01796-1), there was an error with the name of the authors.

The author names Marcela A. Matos and Frances Maratos should be corrected to Marcela Matos and Frances A.
Maratos. The middle initial 'A.' should be the middle initial of Frances A. Maratos.

Thus, this erratum is presented to fix the error.

The original and correction article has been corrected.

Publisher's Note Springer Nature remains neutral with regard to jurisdictional claims in published maps and institutional affiliations.

The original articles can be found online at https://doi.org/10. 1007/s12671-021-01778-3 and https://doi.org/10.1007/s12671021-01796-1.

Marcela Matos

marcela.matos@fpce.uc.pt

1 Center for Research in Neuropsychology and Cognitive and Behavioural Intervention (CINEICC), Faculty of Psychology and Educational Sciences, University of Coimbra, Coimbra, Portugal

2 Universidade Portucalense, Infante D. Henrique, Porto, Portugal

3 Instituto Superior Miguel Torga, Coimbra, Portugal

4 School of Psychology, College of HealthPsychology \& Social Care, University of Derby, Derby, UK

5 Centre for Compassion/Mental Health Research Unit, Derbyshire Healthcare NHS Foundation Trust, Derby, UK 